\title{
COMPARISON OF TITANIUM METAL MATRIX COMPOSITE SURFACE LAYERS PRODUCED DURING LASER GAS NITRIDING OF TI6AI4V ALLOY BY DIFFERENT TYPES OF LASERS
}

\begin{abstract}
The article presents the results of a comparative study of the nitriding process of titanium alloy substrate using two lasers with different characteristics of laser beams. One of the applied lasers was a high power diode laser emitting at a dominant wavelength of $808 \mathrm{~nm}$, with a rectangular laser beam spot, and multimode energy distribution across the spot. The second laser was a solid state Yb:YAG disk laser emitting at a wavelength of $1.03 \mu \mathrm{m}$, with a circular beam spot, characterized by near Gaussian energy distribution across the spot. In a case of both lasers single stringer beads with a similar width and at similar energy input were produced. As a result of melting of the substrate with a laser beam in a pure gaseous nitrogen atmosphere composite surface layers with in situ precipitated titanium nitrides embedded in the metallic matrix of titanium alloy were produced, in both cases. However, the surface topography and structure is different for the surface layers produce by different lasers at the same processing parameters and width of laser beams.
\end{abstract}

Keywords: titanium alloys, laser gas nitriding, composite surface layer, disk laser, diode laser

\section{Introduction}

Titanium and its alloys in particular are attractive structural materials in comparison to many other non-ferrous metals, alloys, and also modern advanced high strength steels (AHSS) [1-9]. Thanks to excellent corrosion resistance, high resistance to thermal and mechanical fatigue caused by vibrations titanium alloys are used for manufacturing components and parts of advanced machinery and equipment [10-20]. Titanium alloys are also used as biomaterials for implants manufacturing [21-25]. However, in the case of moving parts which are subjected to surface wear, the service life is not satisfactory because of medium tribological properties and relatively high friction coefficient [1,26-31]. Therefore different methods of surface modification are widely applied in a case of titanium alloys [1,3,32-37].

The first attempts to modify the surface characteristics of commercially pure titanium by laser surface melting (LSM) in nitrogen rich atmosphere were made by Katayama S. in the early eighties [38]. Then the high potential of this method to modify the surface properties of titanium and titanium alloys was recognized [3,39-42]. The first trials of laser gas nitriding (LGN) of pure titanium were carried out by the available at that time gas $\mathrm{CO}_{2}$ laser, which provided a high enough level of output laser power. Since then, numerous studies of laser nitriding and alloying of pure titanium as well as different titanium alloys were performed worldwide by many researches. However, commonly reported problems refer to cracking of hard nitrided surface layers, and also to excessive roughness of such layers. Despite many years of research, the problem is still present, as evidenced by the number of publications that still appear in the world literature [1-3,21-28,38-55].
Researchers have proposed different approaches and different ways to eliminate cracks in the nitrided surface layers produced on pure titanium or its alloys. For example Mridha S. and Baker T.N. have studied a wide range of laser gas nitriding of pure titanium as well as titanium alloy Ti6Al4V using a $5 \mathrm{~kW}$ gas $\mathrm{CO}_{2}$ laser $[43,44]$. They found that in a case of pure titanium surface cracking can be totally eliminated either by nitriding in dilute nitrogen atmosphere or by controlling the laser parameters and gas flow rate in a pure nitrogen environment [43]. While in the case of titanium alloy Ti6A14V, cracking in $100 \% \mathrm{~N}$ environments depends on the TiN dendrite population in the surface layers. They suggest that by regulating the gas flow rate and heat input, the dendrite population could be controlled to eliminate cracking, but at the expense of hardness [44]. In turn, Hu C. and Baker T.N. investigated laser nitriding of Ti6Al4V to improve the surface properties, using a $5 \mathrm{~kW}$ gas $\mathrm{CO}_{2}$ laser [45]. They indicate that the tendency to cracking is related to the volume fraction of titanium nitrides formed in the melt, and that preheating the material could avoid cracking. While Selamat M.S., Baker T.N. and Watson L.M. investigated laser nitriding of Ti6Al4V titanium alloy under $20 \%$ nitrogen and $80 \%$ argon environment. They used a $5 \mathrm{~kW}$ gas $\mathrm{CO}_{2}$ laser with a spinning beam mode to produce a $4 \mathrm{~mm}$ wide melt track at the spinning velocity of $1500 \mathrm{rpm}$ [46]. They successfully produced crackfree nitrided surface layers but with medium level of hardness in a range of 500 to just $800 \mathrm{HV}$.

In addition to the gas $\mathrm{CO}_{2}$ laser, the studies of titanium nitriding were also conducted with another laser, i.e. the solid state Nd:YAG laser. Both lasers have been used in the world industry for many years as workhorses, providing superior output power and high beam quality in continuous and

\footnotetext{
* SILESIAN UNIVERSITY OF TECHNOLOGY, FACULTY OF MECHANICAL ENGINEERING, WELDING DEPARTMENT, 18 A KONARSKIEGO STR., 44-100 GLIWICE, POLAND

\# Corresponding author: aleksander.lisiecki@polsl.pl
} 
pulse mode operation. Ohtsu N. et al. and Santos E.C. et al. investigated process of titanium nitriding by Nd:YAG lasers $[47,48]$. Ohtsu N. et al found that the effect of irradiation is clearly different for various wavelengths. They reported that craters on the surface layers formed by the 532-nm laser were deeper than those formed by the 1064-nm laser for the same remaining parameters [47]. On the other hand, Santos E.C. et al. showed the difference between laser gas nitriding by Nd:YAG laser in CW, Q-sw and pulsed modes.

In addition, studies of laser surface modification, especially laser nitriding of titanium and titanium alloy were also carried out with other lasers. For example Yue T.M., Yu J.K., Mei Z. and Man H.C indicate the potential and advantages of using an excimer UV laser in surface treatment of Ti-alloys [49]. They pay particular attention to the high absorbability of UV laser radiation by metals, and the extremely short pulse duration, which results in extremely fast cooling rates and hence a much refined and homogenised microstructure. In turn, Carpene E., Shinn M. and Schaaf P. applied free-electron laser for surface processing of titanium in nitrogen atmosphere [50].

Carpene E., Schaaf P., Han M., Lieb K.P. and Shinn M. studied the process of laser nitriding of metals by different lasers with the wavelengths in a range from $0.3-3.0 \mu \mathrm{m}$ [51]. They found that for some metals the wavelength strongly effects the irradiation and efficiency of the nitriding process. Trtica M.S., Gakovic B.M. et al. compared a transversely excited atmospheric (TEA) $\mathrm{CO}_{2}$ and excimer- $\mathrm{KrCl}$ laser for surface modification of TiN coating [52]. They found that the effect of laser irradiation and mechanism of heating, melting and evaporation are different for both lasers.

Thomann A.L., Sicard, E. et al. studied the surface nitriding of titanium and aluminum by laser-induced plasma, using a pulsed $\mathrm{CO}_{2}$ laser and a pulsed excimer $\mathrm{XeCl}$ [53]. They found that the synthesized layers exhibit differences that depend on the type of laser used.

The continuous and dynamic development in the field of laser devices has led to introducing new types and new generations of high power lasers. Among these new generations of high power lasers there are diode lasers, solid state YAG disk lasers and fiber lasers emitting the wavelength in a near infrared band. High power diode lasers (HPDLs) are considered to be advantageous in surface treatment as reported by A. Biswas et al. and M.G. Perez et al., and shown in previous study $[54,55]$. While the main advantage of disk and fiber laser is superior beam quality at relatively high levels of output power, low divergence of the beam, and thus possibility of achieving a small diameter of beam spots.

Therefore, a comparative study of titanium alloy nitriding by the high power diode laser and the disk Yb:YAG laser was carried out.

\section{Material and experimental procedure}

Titanium alloy Ti6Al4V (wt. \%, Grade 5, ASTM B265) is the most commonly used in the industry worldwide. That's why the Ti6Al4V alloy was chosen to the comparative study of laser gas nitriding by two lasers with different characteristics of laser beams. Detailed information on the chemical composition and mechanical properties of the applied titanium alloy are given in the references No. $1,2,21$. Laser gas nitriding tests were conducted by two prototype stands and equipped with automated positioning systems and computer control units. A detailed description of these experimental stands is given in the references No. 1,2,21-28. One of these stands was coupled with a unique high power direct diode laser (HPDDL) ROFIN DL020 with a rectangular beam spot. In the case of direct diode laser the laser beam is emitted directly from the laser head and directly delivered into the processing area. The applied specific diode laser emits in a very near infrared band at the dominant wavelength of $808 \mathrm{~nm}$, which in highly absorbed by metals surfaces. The rectangular beam spot has a width of $1.8 \mathrm{~mm}$ and a length of $6.8 \mathrm{~mm}$, at basic configuration of optics. Another characteristic feature is multimode, uniform energy distribution across the laser beam spot in the longitudinal direction, as shown in Fig. 1.

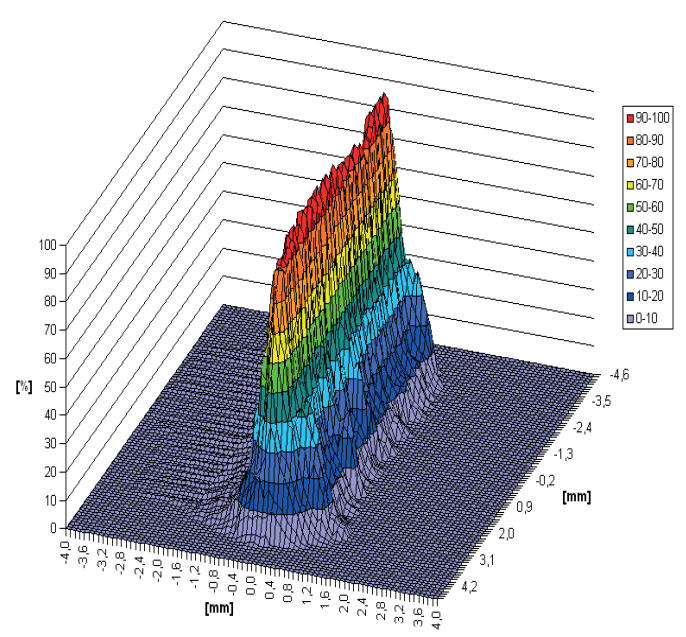

Fig. 1. The spatial distribution of laser beam intensity at the focal plane of HPDDL ROFIN DL 020 [1]

The second laser used in this study was a solid state Yb:YAG disk laser TRUMPF TruDisk 3302. For a change, this specific laser beam has a circular shape with the beam spot dimeter of just $200 \mu \mathrm{m}$. The laser beam is delivered to a focusing head by a fiberglass. The wavelength of the applied disk laser is $1.03 \mu \mathrm{m}$, slightly longer compared to the HPDDL. Detailed information and technical specification of these lasers are provided in references No. 1,2,21-28.

Rectangular specimens of titanium alloy with dimensions of $40 \times 70 \mathrm{~mm}$ were cut from a hot-rolled sheet with a thickness of $3.0 \mathrm{~mm}$. Microstructure of the titanium alloy hot-rolled sheet is shown in Fig. 2. Prior to the nitriding test surfaces of test samples were mechanically ground by 180 -grade $\mathrm{SiC}$ paper to remove oxides and next cleaned by acetone. To provide a fully controlled gas atmosphere, the nitriding tests were conducted inside a gas chamber made of acrylic glass (PMMA). The chamber was evacuated directly before test and filled by pure nitrogen. Laser beam of the HPDDL laser was delivered into the chamber via a cover of acrylic glass which is completely transparent for the wavelength of $808 \mathrm{~nm}$. 


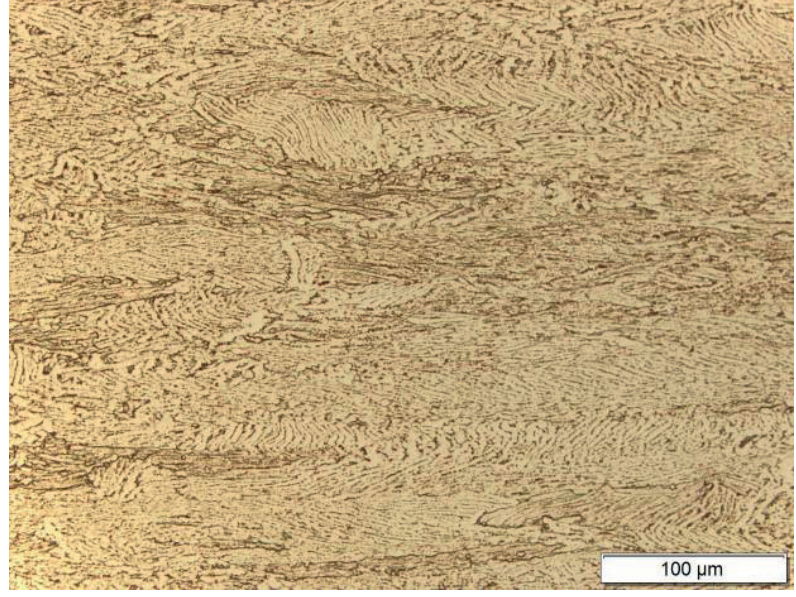

Fig. 2. Microstructure of a hot-rolled sheet of titanium alloy Ti6Al4V $3.0 \mathrm{~mm}$ thick $(\alpha+\beta$ phases $)$

a)

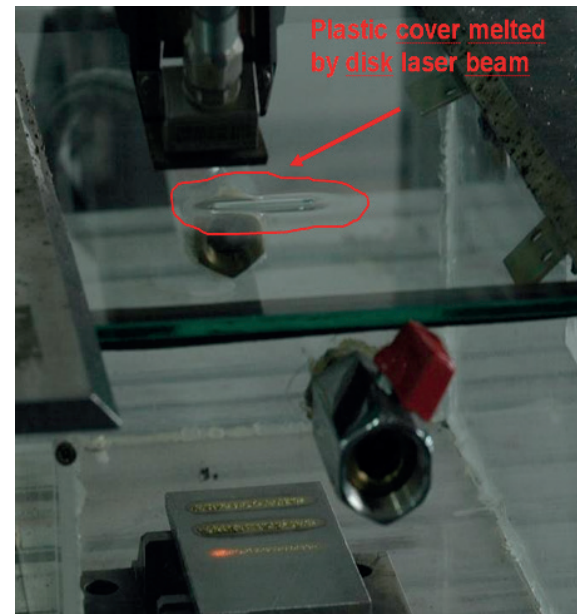

b)

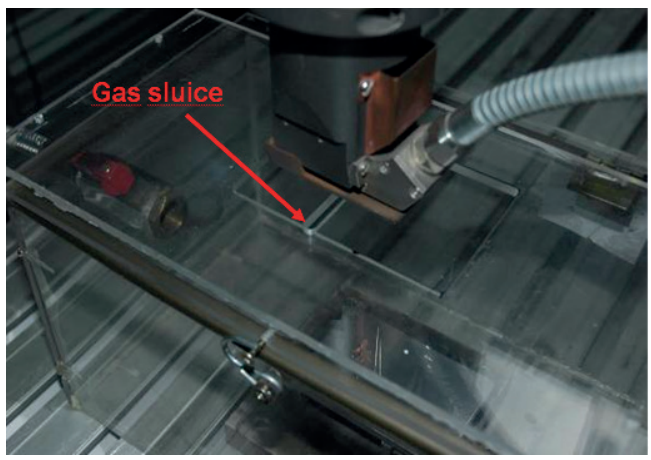

Fig. 3. A view of a melted cover glass by the laser beam of disk laser at output power of $1.8 \mathrm{~kW}$ (a) and a design of a gas sluice for laser beam transmission into the gas chamber (b)
Test surfaces were produced at selected parameters, determined in previous investigations, and considered as optimal for the surface layers produced by means of HPDDL laser [1]. The parameters of laser gas nitriding are given in Table 1.

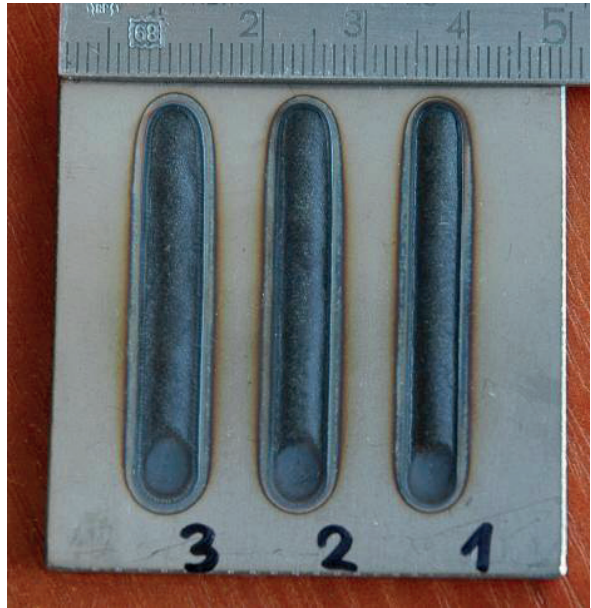

Fig. 4. A view of single stringer beads produced by defocused disk laser beam with a dimeter od $6.8 \mathrm{~mm}$ on the substrate of stainless steel (bead width in a range of 6-6.5 mm)

Preliminary tests with the disk laser beam having longer wavelength of $1.03 \mu \mathrm{m}$ showed that the laser radiation is absorbed to such an extent that it melts the cover made of acrylic glass. Therefore, transmission of the disk laser beam via the cover was not possible at output powers greater than $1.8 \mathrm{~kW}$, Fig 3a. That's why the design of a cover was changed, and a special gas sluice was applied for delivering the disk laser beam inside the chamber, as shown in Fig. 3b. In order to compare the surface layers produced by both lasers, the disk laser beam was defocused in such a way to provide a width (diameter) of $6.8 \mathrm{~mm}$, the same as the laser beam set perpendicularly to the traveling direction. Before the relevant tests of titanium alloy nitriding, single stringer beads on austenitic stainless steel sheet were produced by defocused disk laser beam, to verify the bead width, Fig. 4. As can be seen the width of beads produced on the substrate of stainless steel is approx. 6-6.5 mm, similarly like in a case of HPDDL laser. After nitriding of the titanium alloy, the topography of test surface layers was analyzed by an optical, non-contact Profilograph Micro Prof 100 FRT. Additionally macro and microscopic observations of surface layer structure were performed by means of a stereoscopic optical microscope Olympus SZX9 and metallographic microscope Olympus

TABLE 1

Parameters of laser gas nitriding of titanium alloy Ti6Al4V samples $3.0 \mathrm{~mm}$ thick by the high power direct diode laser ROFIN DL 020 and a solid state Yb:YAG disk laser TRUMPF TruDisk 3302

\begin{tabular}{|c|c|c|c|c|c|}
\hline \hline \multirow{2}{*}{ Parameter No. } & \multirow{2}{*}{$\begin{array}{c}\text { Scanning speed } \\
(\mathbf{m m} / \mathbf{m i n})\end{array}$} & $\begin{array}{c}\text { Output laser power } \\
\text { (W) }\end{array}$ & \multirow{2}{*}{$\begin{array}{c}\text { Heat input } \\
(\mathbf{J} / \mathbf{m m})\end{array}$} & \multicolumn{2}{|c|}{$\begin{array}{c}\text { Power density } \\
\left(\mathbf{W} / \mathbf{c m}^{2}\right)^{*}\end{array}$} \\
\cline { 3 - 6 } & & 1500 & 90 & $1.2 \cdot 10^{4}$ & $4.13 \cdot 10^{3}$ \\
\hline P1 & 1000 & 1800 & 270 & $1.5 \cdot 10^{4}$ & $4.95 \cdot 10^{3}$ \\
\hline P2 & 400 & 1500 & 60 & $1.2 \cdot 10^{4}$ & $4.13 \cdot 10^{3}$ \\
\hline P4 & 1500 & 2000 & 300 & - & $5.5 \cdot 10^{3}$ \\
\hline
\end{tabular}

Remarks: *- power density determined on the area A of laser beam interaction on the top surface of heated sample $\left(\mathrm{A}=0.122 \mathrm{~cm}^{2} \mathrm{HPDL}\right.$ laser beam of size $6.8 \mathrm{x} 1.8 \mathrm{~mm}$, and $\mathrm{A}=0.363 \mathrm{~cm}{ }^{2}$ for the circular defocused beam of disk laser having a diameter of $6.8 \mathrm{~mm}$ ) 
PME3. Microhardness was analyzed and determined across the surface layers from the region directly under the top surface, through the fusion zone, and heat affected zone, to the base metal of the substrate. Results are given in the Figs. from 5 to 13.

\section{Results and discussion}

\subsection{Topography of the surface layers}

The tests of laser gas nitriding of titanium alloy Ti6Al4V substrate by both lasers resulted in formation of golden shiny stringer beads characterized by different roughness and surface topography, Fig. 5-8.

a)

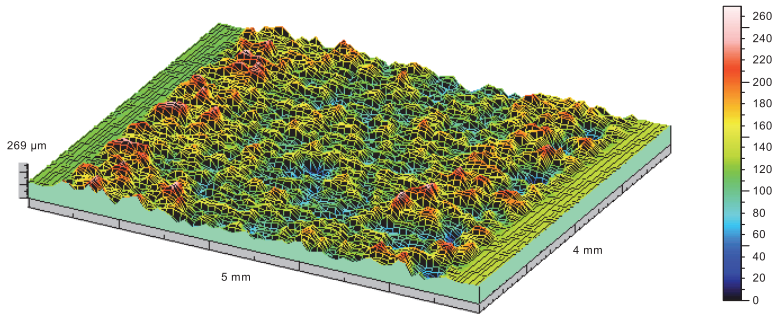

b)

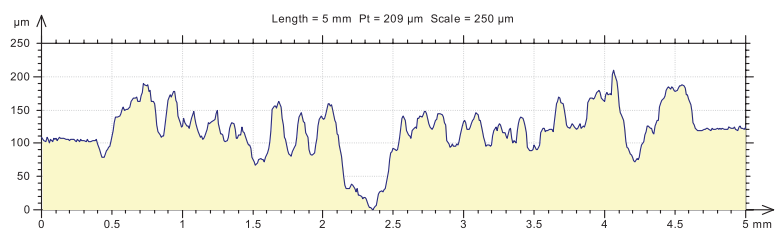

c)

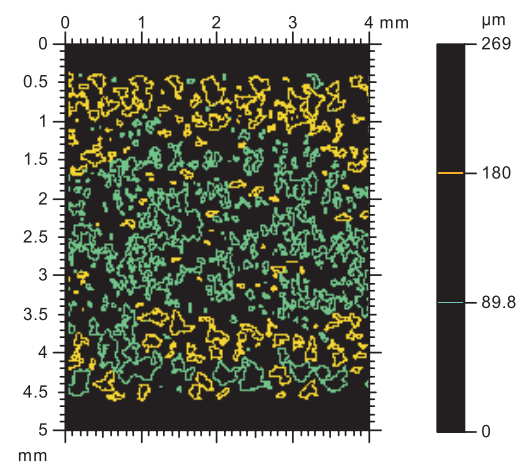

Fig. 5. Surface topography (a), cross-sectional profile (b), and distribution of peaks on the surface (c) of surface layer produced by HPDDL laser at laser power $1.5 \mathrm{~kW}$ and scanning speed $1.5 \mathrm{~m} / \mathrm{min}$, Table 1

When the rectangular diode laser beam with the width of $6.8 \mathrm{~mm}$ (set transversely to direction of traveling), and multimode, even intensity (energy) distribution across the spot was applied, the width of single stringer beads was from 5.8 to $6.0 \mathrm{~mm}$, depending on the parameters of laser nitriding, Fig. 5,6. Additionally, thanks to the change of processing parameters, mainly the laser output power and scanning speed, and hence energy input, the topography of surface layers can be precisely controlled and shaped, as shown in Fig. 5,6. However, previous studies have shown that energy input is not sufficient parameter to predict the properties and topography of surface layers produced by HPDDL laser [1]. Much higher precision and accuracy in prediction the surface layers properties can be achieved by taking into account the power density of the laser beam determined on the irradiated surface, and also the time of laser beam interaction with the surface, as described in the Ref. 1 . In a case of relatively high scanning speeds at the level approx. $1.5 \mathrm{~m} / \mathrm{min}$ or higher and simultaneously output power at least $1.5 \mathrm{~kW}$, the substrate is uniformly melted on the entire width, approximately equal to the width of the laser beam $(6.8 \mathrm{~mm})$.

The topography of surface layers produced under such conditions is regular and the highest distance between the maximum valley depth and the maximum peak height doesn't exceed 200 microns, as can be seen in Fig. 5.

a)

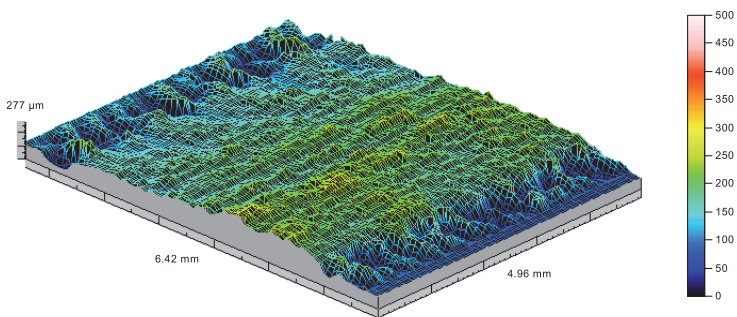

b)

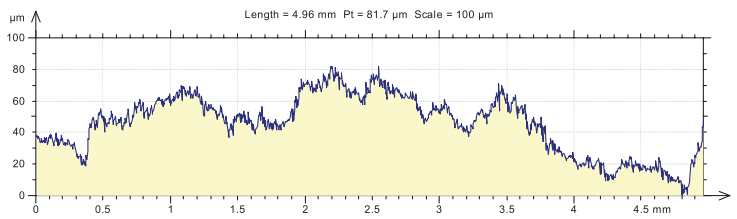

c)

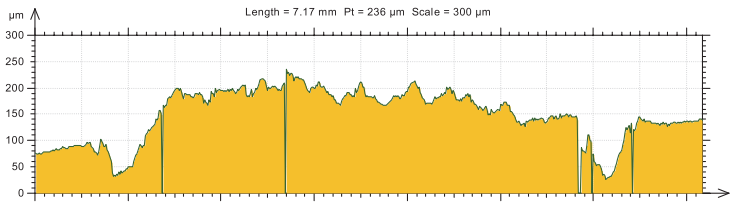

d)

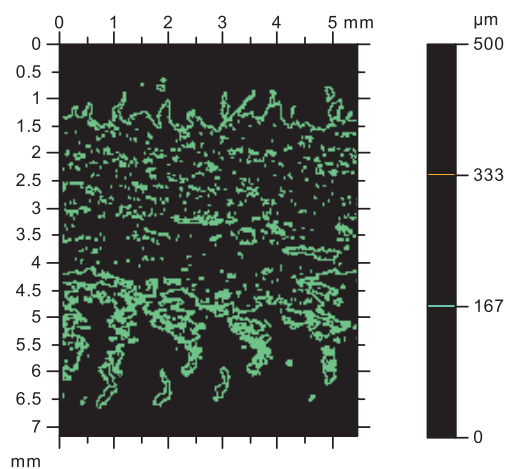

Fig. 6. Surface topography (a), cross-sectional (b), and longitudinal profile (c), and distribution of peaks on the surface (d) of surface layer produced by HPDDL laser at laser power $1.8 \mathrm{~kW}$ and scanning speed $0.4 \mathrm{~m} / \mathrm{min}$, Table 1

On the other hand, at relatively low scanning speeds, at approx. $400 \mathrm{~mm} / \mathrm{min}$, and high power level, the surface becomes even flatter and smooth, Fig. 6. In this case the highest distance between valleys and peaks is below 150 microns, Fig. 6. It is worth noting that the visual inspections, as well as microscope observations and analysis did not reveal any cracks neither micro cracks.

On the other hand the trials of nitriding with the solid state $\mathrm{Yb}$ :YAG laser were made so as to replicate the conditions of nitriding with the HPDDL. Therefore the laser beam 
was defocuses to the diameter of $6.8 \mathrm{~mm}$. The surface layer produced at the laser power $1.8 \mathrm{~kW}$ and scanning speed 400 $\mathrm{mm} / \mathrm{min}$ show different topography, compared to the layer produced at the same parameter by HPDDL laser.

a)

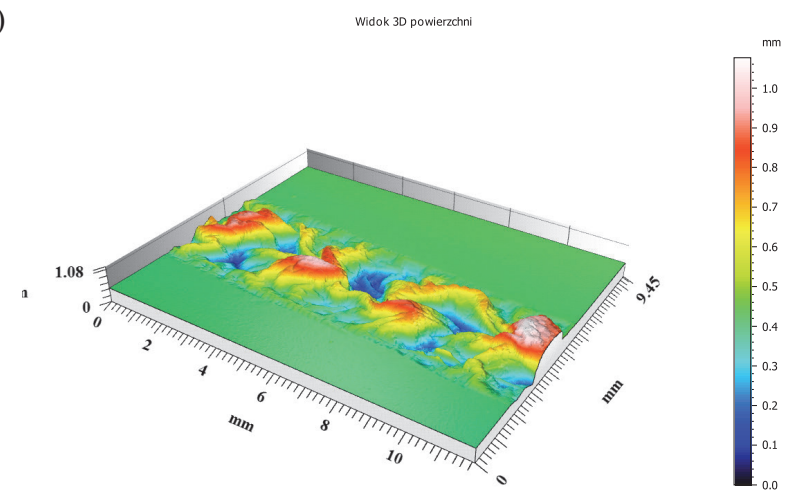

b)

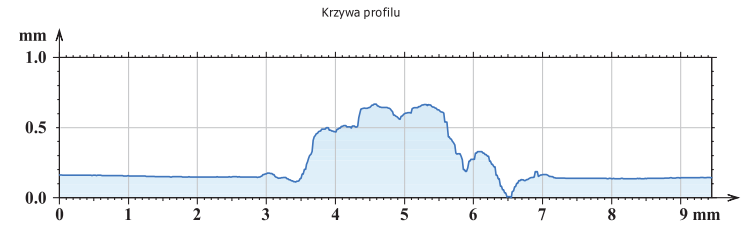

c)

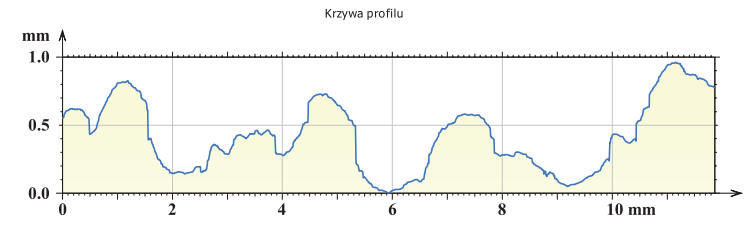

Fig. 7. Surface topography (a), cross-sectional (b), and longitudinal profile (c), of surface layer produced by disk laser at laser power 1.8 $\mathrm{kW}$ and scanning speed $0.4 \mathrm{~m} / \mathrm{min}$, Table 1

Moreover the topography is irregular and the width is lower, Fig. 6. Increasing the output power of the disk laser up to $2.0 \mathrm{~kW}$ did not result in a clear change of the surface topography, as can be seen in Fig. 7. Width of the single stringer beads produced by disk laser at the output power of 1.8 and $2.0 \mathrm{~kW}$ are approx. 4 to $5 \mathrm{~mm}$, so significantly narrower than these produced by HPDDL laser. In turn, the distance between the maximum valley depth and the maximum peak height is approx. $0.65 \mathrm{~mm}$ in a case of the bead produced at the power $1.8 \mathrm{~kW}$ and almost $1.1 \mathrm{~mm}$ in the case of the bead produced at $2.0 \mathrm{~kW}$, Fig. 7.

a)

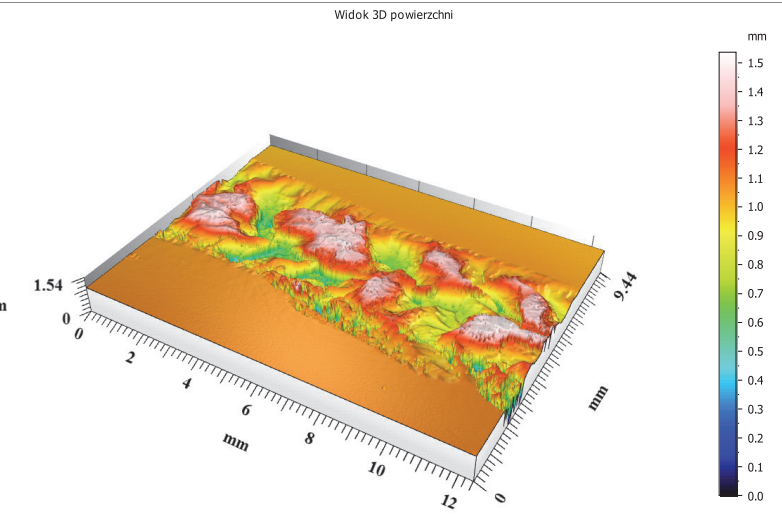

b)

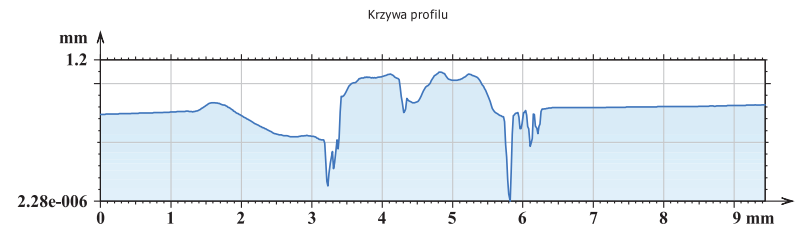

c)

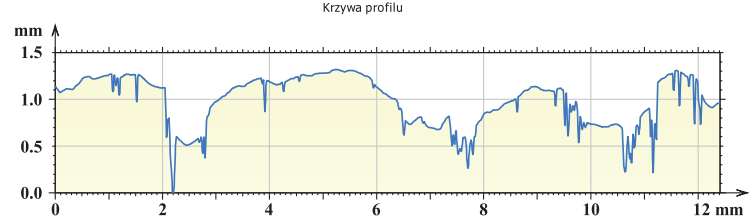

Fig. 8. Surface topography (a), cross-sectional (b), and longitudinal profile (c), of surface layer produced by disk laser at laser power 2.0 $\mathrm{kW}$ and scanning speed $0.4 \mathrm{~m} / \mathrm{min}$, Table 1

The results show clearly that the conditions of heating, melting, and nitriding of the titanium alloy surface under HPDDL and disk laser are different.

\subsection{Structure and microhardness}

Structure of the base metal substrate is typical for twophase alloy sheet after hot-rolling. Plastically deformed regions consisted of Ti $\alpha$ and Ti $\beta$ phases can be observed in Fig. 2 . While the nitrided surface layers exhibit a composite structure with dendritic titanium nitrides embedded in the metallic matrix of titanium alloy, Fig. 9-12. Previous investigations on the phase compositions of surface layers nitrided in pure nitrogen atmosphere by the HPDDL laser beam showed that the dendrites precipitations are mainly TiN at different stoichiometry, and also $\mathrm{Ti}_{2} \mathrm{~N}$ [1]. Below the dendritic structure zone a recrystallized band of martensitic structure can be easily identified, as can be seen in Fig. 11. Population and distribution of the dendritic titanium nitrides depend on the nitriding conditions.

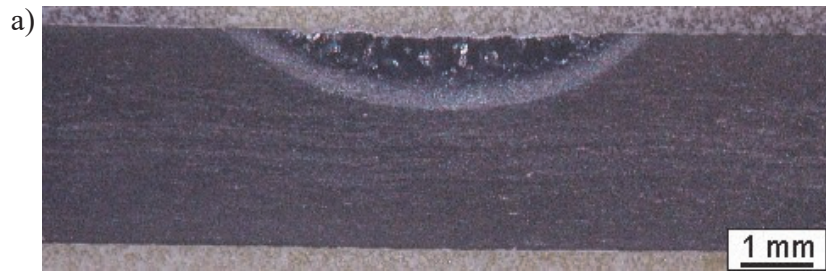

a)

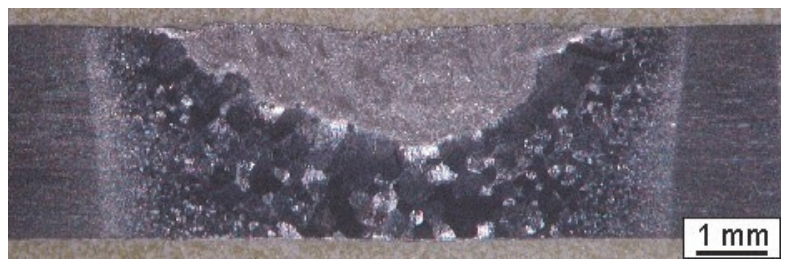

Fig. 10. Macrostructure of cross-sections of surface layers nitrided by disk laser; a) $1.8 \mathrm{~kW}, 0.4 \mathrm{~m} / \mathrm{min}$, b) $2.0 \mathrm{~kW}, 0.4 \mathrm{~m} / \mathrm{min}$, Table 1

The nitrides rich region may very deep, because in a case of the surface layer produced at the output power of HPDDL laser $1.8 \mathrm{~kW}$ and scanning speed $400 \mathrm{~mm} / \mathrm{min}$, the fusion zone with densely arranged nitrides reach up to approx. 1.6-1.7 mm, Fig. 9,11. Additionally no cracks were found in this thick surface layer. The morphology and structure of 
these nitrided surface layers depend on the parameters of processing by the HPDDL laser. Microhardness measurements showed extremely high value of microhardness directly under the surface of thickest surface layer with densely distributed dendritic titanium nitrides.
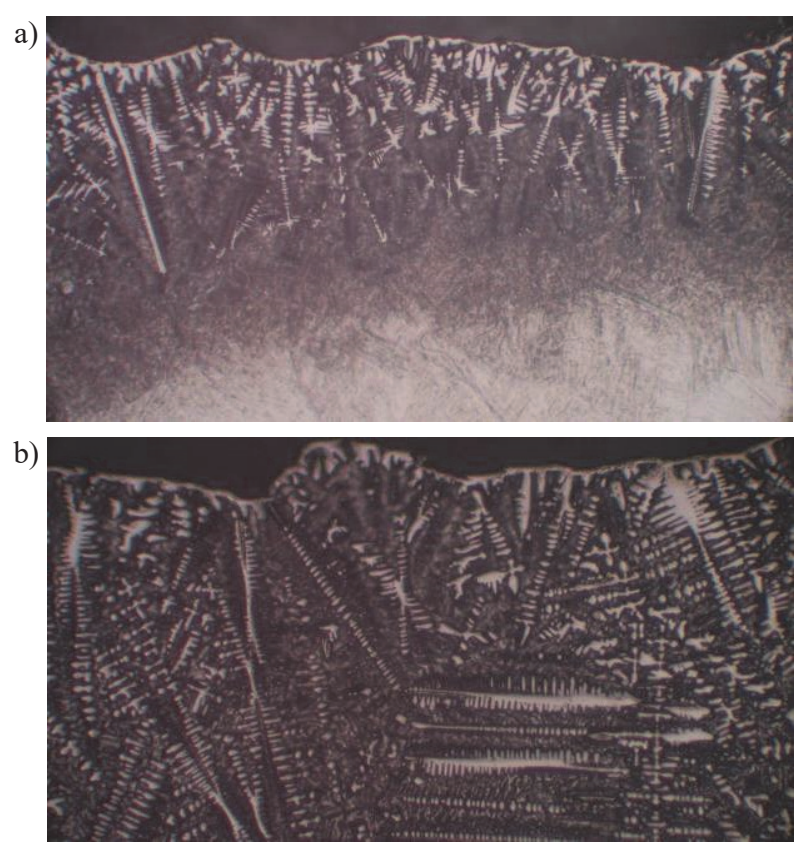

Fig. 11. Structure of cross-sections of surface layers nitrided by HPDDL laser; a) $1.5 \mathrm{~kW}, 1.5 \mathrm{~m} / \mathrm{min}$, b) $1.8 \mathrm{~kW}, 0.4 \mathrm{~m} / \mathrm{min}$, Table 1

The value of microhardness under the surface reached approx. 2400 HV0.2, Fig. 13. Next the microhardness gradually decreases towards the heat affected zone, and reaches the minimum in the base metal, at a level of approx. $330 \mathrm{HV} 0.2$, Fig. 13. Maximum values of microhardness in a case the thinner surface layer, produced at lower energy input, lower output powers, and higher scanning speed, are clearly lower, and oscillate around $1500 \mathrm{HV} 0.2$, Fig. 13.

Structure and morphology of the surface layers produced by the disk laser beam are similar in general to the structures of layers produced by HPDDL laser, Fig. 10,12. However, the depth of the region rich in nitrides, and also the density, population, distribution, and morphology of TiN dendrites are clearly different, Fig. 12.

Similarly the microhardness distribution differs compared to these determined for surface layers produced by HPDDL laser, Fig. 13.

a)

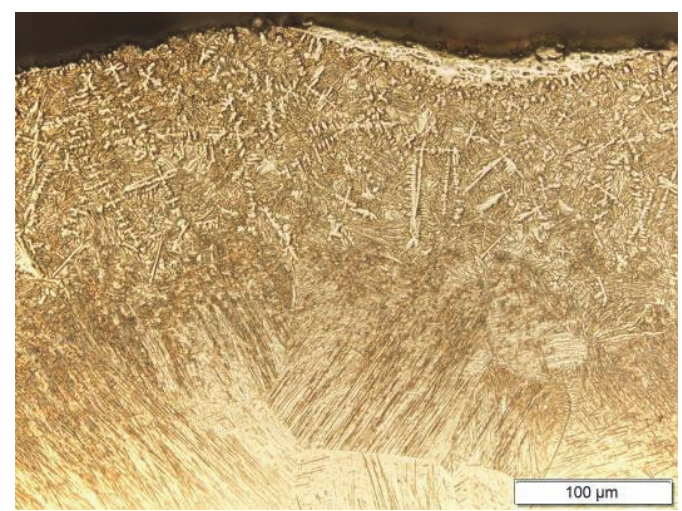

b)

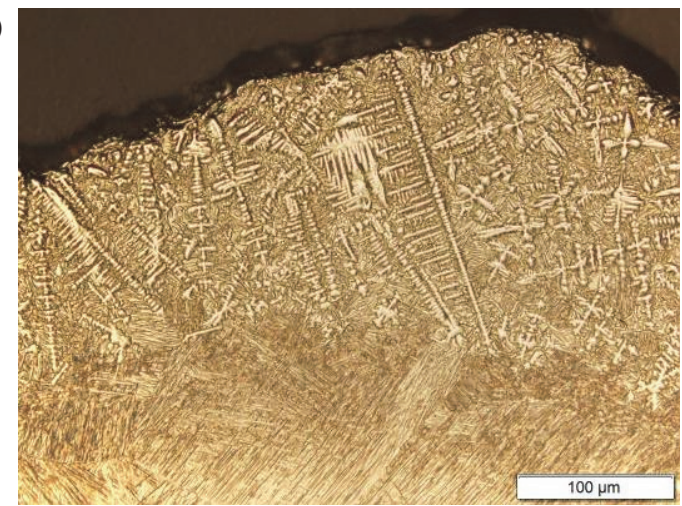

Fig. 12. Structure of cross-sections of surface layers nitrided by disk laser; a) $1.8 \mathrm{~kW}, 0.4 \mathrm{~m} / \mathrm{min}$, b) $2.0 \mathrm{~kW}, 0.4 \mathrm{~m} / \mathrm{min}$, Table 1

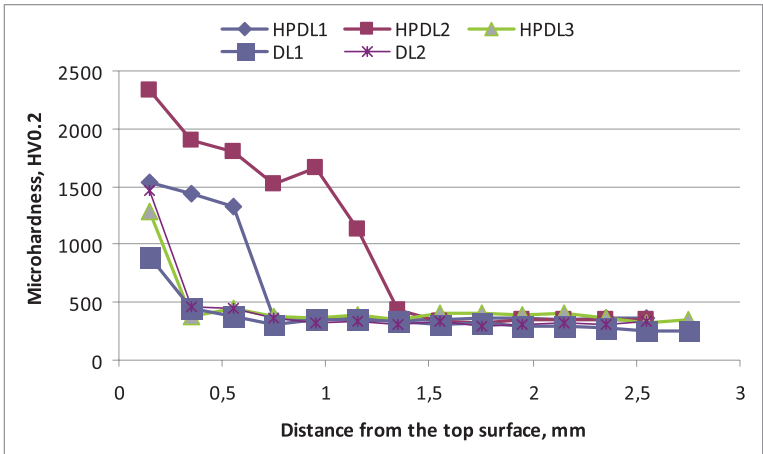

Fig. 13. Microhardness distribution on the cross-section of surface layers, Table 1, (HPDL - diode laser, DL - disk laser)

Maximum microhardness was determined in the surface layer produced at the highest output power of $2.0 \mathrm{~kW}$ at the level of $1450 \mathrm{HV} 0.2$, Fig. 13. The microhardness falls down to $450 \mathrm{HV} 0.2$ at a depth of $0.45 \mathrm{~mm}$.

\section{Summary and conclusions}

The comparative study of the laser gas nitriding of titanium alloy Ti6Al4V by high power diode laser and solid state $\mathrm{Yb}$ :YAG laser indicate that the mechanisms of heating, melting, and nitriding are different for the applied lasers. This phenomenon may be explained by the differences in the wavelength of both lasers, and also by the different shape, and different modes of intensity (energy) distribution across the laser beam. Despite the same width of laser beam irradiated the surface, the power density in both cases is different, because the areas of laser beam interaction are different. The crosssection area of the circular laser beam at the diameter of 6.8 $\mathrm{mm}$ is $0.363 \mathrm{~cm}^{2}$, while the area calculated for the rectangular laser beam of HPDDL laser, which is $6.8 \mathrm{~mm}$ long and 1.8 wide, is equal to $0.122 \mathrm{~cm}^{2}$. Thus, the difference in the size of the cross-section area of the applied laser beams is up to three times. This means that the power density in a case of a circular laser beam is also three times lower, compared to the rectangular laser beam. Additionally the disk laser beam is characterized by almost Gaussian distribution of the intensity, so the real difference in the beam size, and power density is even higher. Moreover Gaussian distribution makes that the heat generating is not uniform across the laser beam, and thus 
on the treated surface. In this connection, it should be expected that temperature gradients also will be higher in a case of circular laser beam.

\section{Acknowledgments}

This work was partially carried out within the project POIR.01.01.01-00-0278/15-01.

\section{REFERENCES}

[1] A. Lisiecki, Metals 5(1), 54 (2015), DOI:10.3390/met5010054.

[2] A. Lisiecki, Advanced Materials Research 1036, 320 (2014).

[3] M. Whittaker, Metals 5, 1437 (2015).

[4] A. Kurc-Lisiecka, et al., Sol. St. Phenomena 203-204, 105 (2013).

[5] A. Klimpel, et al., J. Mat. Proc. Tech. 164-165, 1046-1055 (2005).

[6] M. Bonek, L.A. Dobrzański, Mat. Sci. Forum 654-656, 1848 (2010).

[7] G. Moskal, et al., Sol. St. Phenomena 226, 121 (2015).

[8] D. Janicki, M. Musztyfaga-Staszuk, Stroj Vestn-J Mech E 62 (6), 363-372 (2016).

[9] A. Czuprynski, J. Gorka, M.Adamiak, Metalurgija 55(2), 173176 (2016) (in press).

[10] R. Burdzik, Ł. Konieczny, T. Figlus, Activities of Transport Telematics, Book Series: Communications in Computer and Information Science 395, 418-425 (2013).

[11] R. Burdzik, J. of Vibroeng. 15(4), 2114 (2013).

[12] R. Burdzik, Z. Stanik, J. Warczek, Arch. Metall. Mater. 57(2), 409 (2012).

[13] R. Burdzik, Ł. Konieczny, J. of Vibroeng. 15(4), 1680 (2013).

[14] D. Janicki, Proceedings of SPIE, Laser Technology 2012: Applications of Lasers, 8703 (2013) 87030R DOI: $10.1117 / 12.2013430$

[15] T. Węgrzyn, J. Piwnik, D. Hadryś, Arch. Metall. Mater. 58(4), 1067 (2013).

[16] Ł. Konieczny, R. Burdzik, B. Łazarz, Journal of Vibroengineering 15(4), 2042 (2013).

[17] T. Węgrzyn, J. Piwnik et al., Arch. Metall. Mater., 57(3), 679 (2012).

[18] G. Golański, P. Gawień, J. Słania, Arch. Metall. Mater. 57(2), 1067 (2012)

[19] B. Oleksiak, G. Siwiec, A. Blacha-Grzechnik, J. Wieczorek, Metalurgija 53(4), 605 (2014).

[20] J. Bodzenta, A. Kaźmierczak, T. Kruczek, Journal de Physique IV 129, 20 (2005).
[21] A. Lisiecki, Proceedings of SPIE, Laser Technology 2012: Application of Lasers, 8703 (2013), DOI:10.1117/12.2013431.

[22] W. Sitek, L.A. Dobrzański, J. Mater. Process Tech. 164, 1607 (2005).

[23] W. Sitek, Trans. Famena 34/3, 39 (2010).

[24] L.A. Dobrzanski, et al., App. Surf. Sci. 247, 328 (2005).

[25] A. Lisiecki, Applied Mechanics and Materials 809-810, 357 (2015).

[26] A. Lisiecki, Proceedings of SPIE, Laser Technology 2012: Applications of Lasers, 8703 (2013), DOI:10.1117/12.2013429.

[27] A. Klimpel, et al., J. Mat. Proc. Tech. 170(1-3), 251 (2006).

[28] S. Boncel, J. Górka et al., Polymer Composites 35(3), 523 (2014).

[29] J. Górka, Indian Journal of Engineering and Materials Sciences 22, 497 (2015).

[30] J. Jezierski, K. Janerka, Metalurgija 54(2), 365 (2015).

[31] A. Zieliński, et al., Mater. Sci. Tech-Lond. 32(8), 780 (2016).

[32] A. Grajcar, et al., Adv. in Mat. Sci. and Eng. 2014 (2014).

[33] A. Grajcar, et al., Sol. St. Phenomena 203-204, 34 (2013).

[34] A. Zieliński, et al., Arch. Civ. Mech. Eng. 4, 813 (2016),

[35] L.A. Dobrzański, et al., Mat. Sci. Forum. 437-438, 69 (2003).

[36] M. Bonek, et al., Adv. Mat. Res. 291-294, 1365 (2011).

[37] S. Katayama, et al., Surface hardening of titanium by laser nitriding. In Proceedings of the ICALEO'83, Los Angeles, CA, USA, 14-17 November 1983; pp. 127-134.

[38] K. Janerka et al., J. Mat. Proc. Tech. 214(4), 794 (2014).

[39] L.A. Dobrzanski, W. Sitek et al., J. Mat. Proc. Tech. 157, 102 (2004).

[40] [41] L.A. Dobrzanski, W. Sitek, J. Mat. Proc. Tech. 90, 467 (1999).

[41] L.A. Dobrzanski, W. Sitek et al., J. Mat. Proc. Tech. 56(1-4), 873 (1996).

[42] S. Mridha, T.N., Baker, Mat. Sci. Eng. A199, 229 (1994).

[43] S. Mridha, T.N. Baker, J. Mat. Proc. Tech. 77, 115 (1998).

[44] C. Hu, T.N. Baker, Mat. Sci. Eng. A265, 268 (1999).

[45] M.S. Selamat, T.N. Baker, L.M. Watson, J. Mat. Proc. Tech. 113, 509 (2011).

[46] N. Ohtsu et al., Appl. Surf. Sci. 256, 4522 (2010).

[47] E.C. Santos et al., Surf. Coat. Tech. 201, 1635 (2006).

[48] T.M. Yue, J.K. Yu, Z. Mei, H.C. Man, Mat. Letters 52, 206 (2002).

[49] E. Carpene, M. Shinn, P. Schaaf, Appl. Surf. Sci. 247, 307 (2005).

[50] E. Carpene, P. Schaaf et al., Appl. Surf. Sci. 186, 195 (2002).

[51] M.S. Trtica et al., Appl. Surf. Sci. 225, 362 (2004).

[52] A.L. Thomann et al., Surf. Coat. Technol. 97, 448 (1997).

[53] A. Biswas, L. Li, U.K. Chatterjee, I. Manna, J.D. Majumdar, Metall. Mater. Trans. A 40A, 3031 (2009).

[54] M.G. Perez, Surf. Coat. Technol. 200, 5152 (2006). 
